\title{
Proceeding
}

Supplementary Issue: Spring Conferences of Sports Science. Costa Blanca Sports Science Events, 19-20 June 2020. Alicante, Spain.

\section{A novel global postural alteration? Qualitative assessment of hallux valgus and swallowing disorder in human posture: A preliminary investigation on the incidence during age span for promoting psycho-physical and postural well-being}

\author{
VALERIO GIUSTINO1,2 $\triangle$, LUCA RUSSO 2,3, ROSARIO EMANUELE TOSCANO², GIUSEPPE SECOLO², \\ INNOCENZO SECOLO ${ }^{2}$, GIUSEPPE BATTAGLIA ${ }^{1,4}$, GIUSEPPE MESSINA ${ }^{1,2}$ \\ ${ }^{1}$ Department of Psychology, Educational Science and Human Movement, University of Palermo, Palermo, Italy \\ 2 Laboratory of Posture and Biomechanics, University of Palermo, Palermo, Italy \\ ${ }^{3}$ Department of Biotechnology and Applied Clinical Science, University of L'Aquila, L'Aquila, Italy \\ ${ }^{4}$ Regional Sports School of CONI Sicilia; Palermo, Italy
}

\begin{abstract}
Hallux Valgus (HV) and Swallowing Disorder (SD) are two multifactorial postural and biomechanical alterations. It is very important to look for the incidence of these two conditions in order to promote psycho-physical and postural wellbeing. Our study aimed to clinically assess the presence of HV and SD in a large group with different ages spans. Fours skilled professionals performed the assessment following clinical criteria. A total of 61 volunteers subjects (163.5 $\pm 14.1 \mathrm{~cm} ; 59.7 \pm 15.7 \mathrm{~kg} ; 22.9 \pm 13.2 \mathrm{yrs}$.) were selected for the study. The $51 \%$ of the sample showed the HV alteration, $30 \%$ and $73 \%$ respectively for male and female. Regarding ages cluster, the HV was present in $44 \%$ under $20 \mathrm{yrs}$., in $53 \%$ between 21 and $40 \mathrm{yrs}$., in $75 \%$ over $40 \mathrm{yrs}$. The $46 \%$ of the sample showed a SD condition, $50 \%$ and $42 \%$ respectively for male and female. As for ages cluster, the incidence of SD was in $50 \%$ of subjects under $20 \mathrm{yrs.,}$ in $41 \%$ between 21 and 40 yrs., in $50 \%$ over 40 yrs. The $39 \%$ of subjects with HV showed a SD condition. On the other hand, the $43 \%$ of subjects with SD showed the HV deformity. HV and SD are postural disorders and most often occur together. In this framework, HV and SD should be interpreted as sign of global postural alteration and for this reason it is fundamental to assess them. Further research is needed on these two parameters in order to find out the optimal relationship between $\mathrm{HV}$ and SD.

Keywords: Hallux valgus; Swallowing disorder; Posture; Foot; Tongue.

Cite this article as:

Giustino, V., Russo, L., Toscano, R.E., Secolo, G., Secolo, I., Battaglia, G., \& Messina, G. (2020). A novel global postural alteration? Qualitative assessment of hallux valgus and swallowing disorder in human posture: A preliminary investigation on the incidence during age span for promoting psycho-physical and postural well-being. Journal of Human Sport and Exercise, 15(3proc), S833-S839. doi:https://doi.org/10.14198/jhse.2020.15.Proc3.34

Corresponding author. Department of Psychology, Educational Science and Human Movement, University of Palermo, Palermo, Italy. https://orcid.org/0000-0002-4575-8021

E-mail: valerio.giustino@unipa.it

Supplementary Issue: Spring Conferences of Sports Science. Costa Blanca Sports Science Events, 19-20 June 2020. Alicante, Spain.

JOURNAL OF HUMAN SPORT \& EXERCISE ISSN 1988-5202

(c) Faculty of Education. University of Alicante

doi:10.14198/jhse.2020.15.Proc3.34
\end{abstract}




\section{INTRODUCTION}

Human posture is a global complex system depends on a feedback and feedforward process that involves sensory organs and neural mechanisms (Cioncoloni et al., 2016; Deliagina et al., 2012). Since the body posture is continuously regulated on the basis of multisensory information that reaches the central nervous system (CNS) simultaneously, a non-physiological function of one or more of these organs causes different postural disorders (Chin, 2018; Dieterich and Staab, 2017; Saito et al., 2009).

Among the foot postural disorders, hallux valgus (HV) represents a common alteration of the forefoot which affects both genders with higher prevalence among female and diagnosed more frequently in adults (Hecht and Lin, 2014; Perera et al., 2011). In a seminal work, the HV deformity was defined by Hueter as a lateral deviation of the great toe at the metatarsophalangeal joint (Hueter, 1877). The HV development occurs in several stages and its etiology involves both intrinsic and extrinsic factors (Perera et al., 2011). Due to the direct interaction between foot and ground, several studies have investigated the influence of HV deformity in many aspects of human movement as walking, running and in body posture features as balance (CinarMedeni et al., 2016; Hida et al., 2017; Xiang et al., 2018).

In a similar way, many research groups have studied the influence of the stomatognathic system on several physical fitness in patients as well as in healthy people, including athletes (G. Battaglia et al., 2016; G. Battaglia et al., 2018; Wakasugi et al., 2017; Yoshimi et al., 2018). Indeed, due to the biomechanical interaction between the cranio-cervical-mandibular structures, the tongue movement has an effect on neck and upper body muscles influencing the head posture (Messina et al., 2019). Consequently, through the connection with the spine, the head can modify the whole body posture (Shaghayegh Fard et al., 2016; Szczygiel et al., 2019). Since swallowing disorder (SD) is an alteration of the physiological tongue movement that occurs during the act of swallowing, this phenomenon can adversely affect human posture (Begnoni et al., 2019; Bocquet et al., 2008; Machado Junior and Crespo, 2012; Messina et al., 2019).

It is well known that non-physiological afferents coming from altered organs can negatively affect body posture through biomechanical connections and myofascial chains between the different segments of the body (Messina, 2020; Ridola and Palma, 2001; Wilke, Krause, et al., 2016). For this reason, our hypothesis is that, through the myofascial chains, the presence of these two postural alterations could be concurrent and considered as a global postural alteration.

Hence, the aim of this preliminary investigation was to assess the incidence of hallux valgus and swallowing disorder in a large group with different ages spans and investigate any relationship between these two postural alterations in order to promote psycho-physical and postural well-being.

\section{METHODS}

\section{Participants}

A total of 61 subjects (163.5 $\pm 14.1 \mathrm{~cm} ; 59.7 \pm 15.7 \mathrm{~kg} ; 22.9 \pm 13.2 \mathrm{yrs}$.), 30 males and 31 females, were randomly recruited and they signed an informed consent to voluntarily participate in the study. The study was approved by the local ethics committee.

The following exclusion criteria were established for sampling: musculoskeletal and neurological diseases, musculoskeletal injuries, orthopaedic surgeries. Regarding the inclusion criteria, the participation in the study was aimed at subjects aged between 6 and 60 years. 
The sampling was carried out performing postural screening in different locations in Sicily which: the metropolitan city of Catania, and the cities of Mazara del Vallo (Trapani) and Gela (Caltanissetta).

\section{Procedure}

Fours skilled professionals performed the assessment according to clinical criteria. In particular, the same procedure used in a previous work by Messina et al was used to test the swallowing function (Messina et al., 2019). As concern the qualitative assessment of hallux valgus, an clinical evaluation was carried out, including physical examination and alignment observation of the first metatarsophalangeal joint (Hecht and Lin, 2014).

\section{Statistical analysis}

In order to study the incidence of these two postural disorders we firstly calculated the percentage (\%) of subjects that showed HV and SD. Afterwards, for both postural disorders we computed the percentage (\%) as for gender (male and female) and three age classifications (< 20 yrs.; $21<$ yrs. $<40$; $>40$ yrs.). Finally, we calculated the percentage (\%) of subjects with HV who also showed SD and vice versa.

\section{RESULTS}

As concern the presence of $\mathrm{HV}$, the $51 \%$ of the sample showed this condition with an incidence of $30 \%$ for male and $73 \%$ for female (Figure 1). Regarding the ages cluster, the HV was present in $44 \%$ of subjects under 20 yrs., in $53 \%$ of subjects between 21 and 40 yrs., and in $75 \%$ of subjects over 40 yrs.

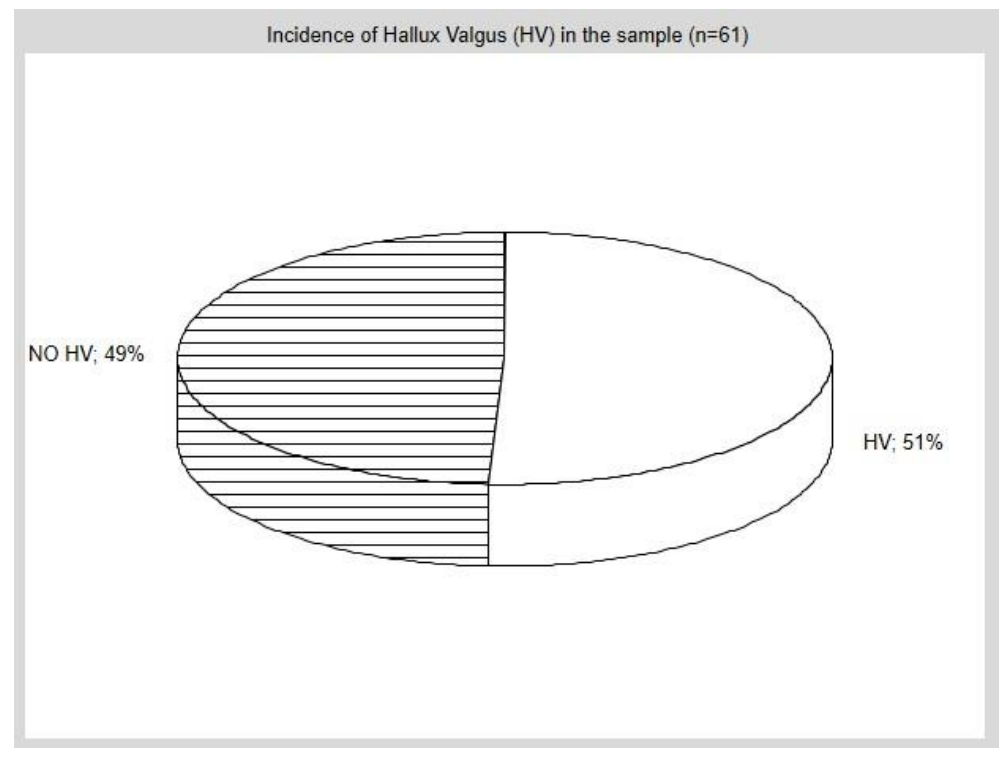

Figure 1. Incidence of Hallux Valgus (HV) in the sample $(n=61)$.

As regard the SD incidence, the $46 \%$ of the entire sample showed this postural alteration with higher rates in male than female participants, $50 \%$ and $42 \%$ respectively (Figure 2 ). Based on age classifications used, the presence of SD was in 50\% of subjects under 20 yrs., in $41 \%$ of subjects between 21 and 40 yrs., and in $50 \%$ of subjects over 40 yrs. 
Moreover, the $39 \%$ of subjects with HV deformity showed a SD condition. On the other hand, the $43 \%$ of subjects with SD showed HV deformity.

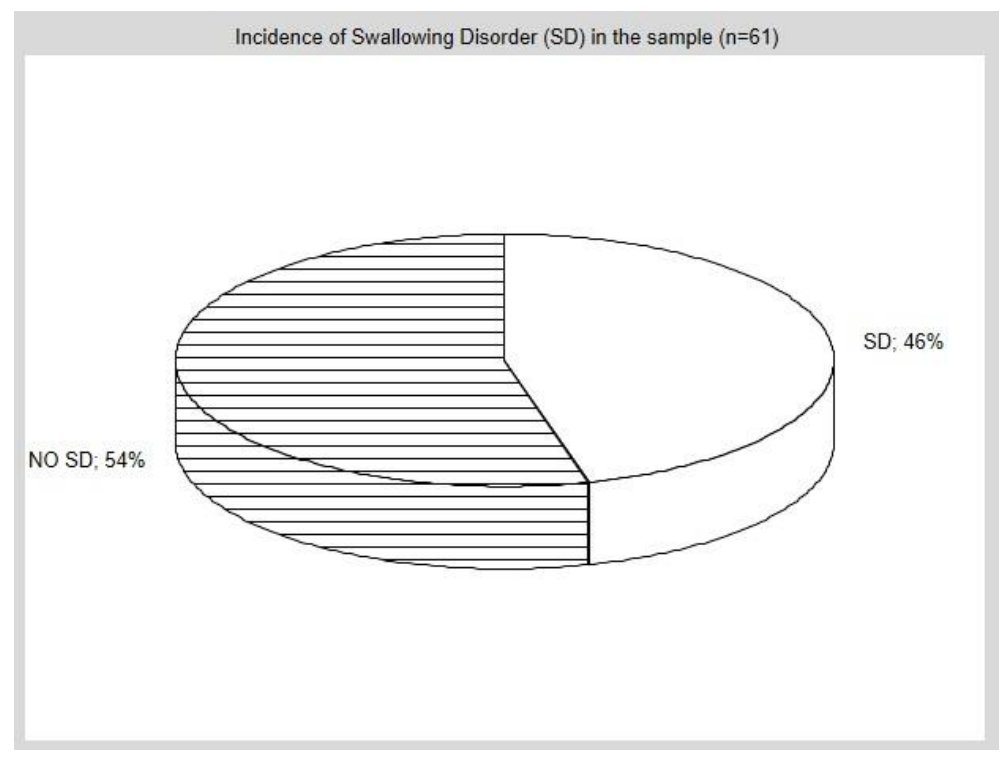

Figure 2. Incidence of Swallowing Disorder $(S D)$ in the sample $(n=61)$.

\section{DISCUSSION}

The aim of our preliminary study was to investigate the incidence of hallux valgus and swallowing disorder in a large group with different ages spans in order to promote psycho-physical and postural well-being. Moreover, further purpose of the study was to evaluate any relationship between these two postural alterations in order to suggest the simultaneous presence of these two disorders as a global postural alteration. In fact, through the myofascial chains, our hypothesis was to find the concurrent presence of HV and SD in most of the sample.

The results found do not allow us to confirm our hypothesis and to establish with certainty the relationship between HV and SD. The incidence of these postural alterations was found in approximately half of the sample recruited, $51 \%$ and $46 \%$ for HV and SD, respectively. HV deformity was present with higher rates in female subjects (73\%) and in subjects over 40 yrs. (75\%). Our findings are consistent with the scientific literature showing that this condition is diagnosed more frequently in female than in men and in adults than in children (Hecht and Lin, 2014). As concern the high incidence rates of SD that we found both for male and female (50\% vs. $42 \%$, respectively) and for the ages cluster used $(50 \%, 41 \%$, and $50 \%$ for subjects under 20 yrs., between 21 and 40 yrs., and over 40 yrs., respectively), our outcomes are partially in agreement with those of some research group (Bhattacharyya, 2015; Monaco et al., 2006). Indeed, our results are in agreement with Monaco et al who found that almost the $50 \%$ of the entire sample they involved showed an atypical swallowing with a similar distribution between gender (Monaco et al., 2006). In contrast with our findings, Bhattacharyya reported a lesser rate of swallowing disorder among children (Bhattacharyya, 2015).

It is well known that sensorial alteration of postural receptors, as HV and SD, influence body balance and postural control (Alghadir et al., 2015; Cuccia and Caradonna, 2009; Gur et al., 2017; Lee and Lee, 2016; Sadra et al., 2013; Vuillerme et al., 2007). In a recent article, Çınar-Medeni et al performed a single-limb 
stance test in a sample of healthy male subjects without and with HV reporting a lower postural stability in the latter group (Cinar-Medeni et al., 2016). In a similar way, Hida et al demonstrated that subjects with HV showed higher plantar pressure on the central region of the forefoot than controls during walking (Hida et al., 2017). Analogously, many researches showed the influence of swallowing on static postural control and a SD may lead to skeletal and muscular disorders (Alghadir et al., 2017; Lumbau et al., 2011).

In effect, the muscular system is morphologically connected by connective tissue forming a structural continuity through myofascial chains (Wilke, Engeroff, et al., 2016; Wilke and Krause, 2019; Wilke, Krause, et al., 2016). In the seminal work by Meyers, the author defined the musculoskeletal system as a tensegrity structure composed of myofascial meridians (Myers, 2001). Among the latter, the Deep Front Line myofascia consists of deep muscles, in continuity through the connective tissue, which extends from the toes of the foot, including the hallux, to the tongue (Myers, 2001). Moreover, the author suggests a postural function as well as a movement function of this myofascial track, playing a key role in body balance and during walking (Myers, 2001).

Based on these premises, we supposed that two postural disorders in distant parts of the body as HV and $\mathrm{SD}$, due to the direct connection can be exist concurrent and being related. However, based on our results we are not able to confirm the simultaneous existence of these two postural disorders and to define it as a global postural alteration.

\section{CONCLUSIONS}

To the best of our knowledge this is the first study that investigated the relationship between hallux valgus and swallowing disorder and further research is needed on these two parameters in order to find out the optimal relationship between HV and SD. If this hypothesis will be confirmed, it could be useful for movement specialists in order to establish the most suitable protocol for promoting psycho-physical and postural wellbeing in these subjects (Francavilla and Francavilla, 2013; Maio et al., 2020).

\section{REFERENCES}

Alghadir, A. H., Zafar, H., Al-Eisa, E. S., \& Iqbal, Z. A. (2017). Effect of posture on swallowing. Afr Health Sci, 17(1), 133-137. https://doi.org/10.4314/ahs.v17i1.17

Alghadir, A. H., Zafar, H., \& Iqbal, Z. A. (2015). Effect of tongue position on postural stability during quiet standing in healthy young males. Somatosens Mot Res, 32(3), 183-186. https://doi.org/10.3109/08990220.2015.1043120

Battaglia, G., Giustino, V., lovane, A., Bellafiore, M., Martines, F., Patti, A., . . Palma, A. (2016). Influence of Occlusal Vertical Dimension on Cervical Spine Mobility in Sports Subjects. Acta Medica Mediterranea, 32(5), 1589-1595.

Battaglia, G., Messina, G., Giustino, V., Zangla, D., Barcellona, M., lovane, A., \& Palma, A. (2018). Influence of Vertical Dimension of Occlusion on Peak Force During Handgrip Tests in Athletes. Asian J Sports Med, 9(4), e68274. https://doi.org/10.5812/asjsm.68274

Begnoni, G., Cadenas de Llano-Perula, M., Willems, G., Pellegrini, G., Musto, F., \& Dellavia, C. (2019). Electromyographic analysis of the oral phase of swallowing in subjects with and without atypical swallowing: A case-control study. J Oral Rehabil, 46(10), 927-935. https://doi.org/10.1111/joor.12826

Bhattacharyya, N. (2015). The prevalence of pediatric voice and swallowing problems in the United States. Laryngoscope, 125(3), 746-750. https://doi.org/10.1002/lary.24931 
Bocquet, E., Moreau, A., Honore, J., \& Doual, A. (2008). [Does dysfunctional swallowing influence posture?]. Orthod $\mathrm{Fr}, 79(2), 115-125$.

Chin, S. (2018). Visual vertigo: Vertigo of oculomotor origin. Med Hypotheses, 116, 84-95. https://doi.org/10.1016/i.mehy.2018.04.025

Cinar-Medeni, O., Atalay Guzel, N., \& Basar, S. (2016). Mild hallux valgus angle affects single-limb postural stability in asymptomatic subjects. J Back Musculoskelet Rehabil, 29(1), 117-121. https://doi.org/10.3233/BMR-150606

Cioncoloni, D., Rosignoli, D., Feurra, M., Rossi, S., Bonifazi, M., Rossi, A., \& Mazzocchio, R. (2016). Role of brain hemispheric dominance in anticipatory postural control strategies. Exp Brain Res, 234(7), 1997-2005. https://doi.org/10.1007/s00221-016-4603-y

Cuccia, A., \& Caradonna, C. (2009). The relationship between the stomatognathic system and body posture. Clinics (Sao Paulo), 64(1), 61-66. https://doi.org/10.1590/S1807-59322009000100011

Deliagina, T. G., Zelenin, P. V., \& Orlovsky, G. N. (2012). Physiological and circuit mechanisms of postural control. Curr Opin Neurobiol, 22(4), 646-652. https://doi.org/10.1016/j.conb.2012.03.002

Dieterich, M., \& Staab, J. P. (2017). Functional dizziness: from phobic postural vertigo and chronic subjective dizziness to persistent postural-perceptual dizziness. Curr Opin Neurol, 30(1), 107-113. https://doi.org/10.1097/WCO.0000000000000417

Francavilla, G., \& Francavilla, V. C. (2013). Physical exercise is terapy - L'attività motoria è terapia. Med Sport, 66(4), 625-628.

Gur, G., Ozkal, O., Dilek, B., Aksoy, S., Bek, N., \& Yakut, Y. (2017). Effects of Corrective Taping on Balance and Gait in Patients With Hallux Valgus. Foot Ankle Int, 38(5), 532-540. https://doi.org/10.1177/1071100716683347

Hecht, P. J., \& Lin, T. J. (2014). Hallux valgus. Med Clin North Am, 98(2), 227-232. https://doi.org/10.1016/i.mcna.2013.10.007

Hida, T., Okuda, R., Yasuda, T., Jotoku, T., Shima, H., \& Neo, M. (2017). Comparison of plantar pressure distribution in patients with hallux valgus and healthy matched controls. J Orthop Sci, 22(6), 10541059. https://doi.org/10.1016/i.jos.2017.08.008

Hueter, C. (1877). Klinik der Gelenkkrankheiten mit Einschluss der Orthopädie (Vol. 2): Leipzig: Verlag Von F. C. W. Vogel.

Lee, S. M., \& Lee, J. H. (2016). Effects of balance taping using kinesiology tape in a patient with moderate hallux valgus: A case report. Medicine (Baltimore), 95(46), e5357. https://doi.org/10.1097/MD.0000000000005357

Lumbau, A., Schinocca, L., \& Chessa, G. (2011). Influence of posture on swallowing. Eur J Paediatr Dent, 12(3), 171-174.

Machado Junior, A. J., \& Crespo, A. N. (2012). Postural evaluation in children with atypical swallowing: radiographic study. J Soc Bras Fonoaudiol, 24(2), 125-129. https://doi.org/10.1590/S2179$\underline{64912012000200006}$

Maio, G. D., Monda, V., Messina, A., Polito, R., Monda, M., Tartaglia, N., .. Francavilla, V. C. (2020). Physical activity and modification of lifestyle induce benefits on the health status. Acta Medica Mediterranea, 36(3), 1913-1919. https://doi.org/10.19193/0393-6384_2020_3_299

Messina, G. (2020). The role of the styloid apophysis of the temporal bone in the biomechanics of the tongue, mandible, hyoid system: a case study. Eur J Transl Myol, 30(1), 8808. https://doi.org/10.4081/ejtm.2019.8808

Messina, G., Giustino, V., Martines, F., Rizzo, S., Pirino, A., \& Scoppa, F. (2019). Orofacial muscles activity in children with swallowing dysfunction and removable functional appliances. Eur J Transl Myol, 29(3), 8267. https://doi.org/10.4081/ejtm.2019.8267 
Monaco, A., Cattaneo, R., Spadaro, A., Marchetti, E., \& Barone, A. (2006). Prevalence of atypical swallowing: a kinesiographic study. Eur J Paediatr Dent, 7(4), 187-191.

Myers, T. W. (2001). Anatomy Trains: Myofascial Meridians for Manual and Movement Therapists (1st ed.): Churchill Livingstone.

Perera, A. M., Mason, L., \& Stephens, M. M. (2011). The pathogenesis of hallux valgus. J Bone Joint Surg Am, 93(17), 1650-1661. https://doi.org/10.2106/JBJS.H.01630

Ridola, C., \& Palma, A. (2001). Functional anatomy and imaging of the foot. Ital J Anat Embryol, 106(2), 85-98.

Sadra, S., Fleischer, A., Klein, E., Grewal, G. S., Knight, J., Weil, L. S., Sr., . . Najafi, B. (2013). Hallux valgus surgery may produce early improvements in balance control: results of a cross-sectional pilot study. J Am Podiatr Med Assoc, 103(6), 489-497. https://doi.org/10.7547/1030489

Saito, E. T., Akashi, P. M., \& Sacco Ide, C. (2009). Global body posture evaluation in patients with temporomandibular joint disorder. Clinics (Sao Paulo), 64(1), 35-39. https://doi.org/10.1590/S1807$\underline{59322009000100007}$

Shaghayegh Fard, B., Ahmadi, A., Maroufi, N., \& Sarrafzadeh, J. (2016). Evaluation of forward head posture in sitting and standing positions. Eur Spine J, 25(11), 3577-3582. https://doi.org/10.1007/s00586-015-4254-x

Szczygiel, E., Sieradzki, B., Maslon, A., Golec, J., Czechowska, D., Weglarz, K., . . Golec, E. (2019). Assessing the impact of certain exercises on the spatial head posture. Int $\mathrm{J}$ Occup Med Environ Health, 32(1), 43-51. https://doi.org/10.13075/ijomeh.1896.01293

Vuillerme, N., Pinsault, N., Chenu, O., Boisgontier, M., Demongeot, J., \& Payan, Y. (2007). How a plantar pressure-based, tongue-placed tactile biofeedback modifies postural control mechanisms during quiet standing. Exp Brain Res, 181(4), 547-554. https://doi.org/10.1007/s00221-007-0953-9

Wakasugi, Y., Tohara, H., Machida, N., Nakane, A., \& Minakuchi, S. (2017). Can grip strength and/or walking speed be simple indicators of the deterioration in tongue pressure and jaw opening force in older individuals? Gerodontology, 34(4), 455-459. https://doi.org/10.1111/ger.12292

Wilke, J., Engeroff, T., Nurnberger, F., Vogt, L., \& Banzer, W. (2016). Anatomical study of the morphological continuity between iliotibial tract and the fibularis longus fascia. Surg Radiol Anat, 38(3), 349-352. https://doi.org/10.1007/s00276-015-1585-6

Wilke, J., \& Krause, F. (2019). Myofascial chains of the upper limb: A systematic review of anatomical studies. Clin Anat, 32(7), 934-940. https://doi.org/10.1002/ca.23424

Wilke, J., Krause, F., Vogt, L., \& Banzer, W. (2016). What Is Evidence-Based About Myofascial Chains: A Systematic Review. Arch Phys Med Rehabil, 97(3), 454-461. https://doi.org/10.1016/j.apmr.2015.07.023

Xiang, L., Mei, Q., Fernandez, J., \& Gu, Y. (2018). Minimalist shoes running intervention can alter the plantar loading distribution and deformation of hallux valgus: A pilot study. Gait Posture, 65, 65-71. https://doi.org/10.1016/j.gaitpost.2018.07.002

Yoshimi, K., Hara, K., Tohara, H., Nakane, A., Nakagawa, K., Yamaguchi, K., . . Minakuchi, S. (2018). Relationship between swallowing muscles and trunk muscle mass in healthy elderly individuals: $A$ cross-sectional study. Arch Gerontol Geriatr, 21-26. https://doi.org/10.1016/j.archger.2018.07.018

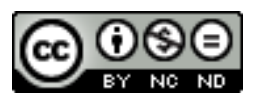

This work is licensed under a Attribution-NonCommercial-NoDerivatives 4.0 International (CC BY-NC-ND 4.0). 